\title{
The association between sexual function and body image among postmenopausal women: a cross-sectional study
}

Soheila Nazarpour ${ }^{1}$, Masoumeh Simbar ${ }^{2,3^{*}}$, Mobina Khorrami ${ }^{3}$, Zahra Jafari Torkamani ${ }^{3}$, Reyhaneh Saghafi ${ }^{3}$ and Hamid Alavi-Majd ${ }^{4}$

\begin{abstract}
Background: Postmenopause physiological changes may alter body image (BI) during the postmenopausal period of life. Body image dissatisfaction may have negative effects on the sexual function of women. The present study aims to assess the relationship between body image and sexual function during the postmenopausal period.

Methods: This cross-sectional study was performed on 231 postmenopausal women who were menopausal during the recent 5 years, aged $>40$ years old, and referring to health centers in Tehran-Iran. The participants were recruited using a multi-stage sampling method. Data were collected using 3 questionnaires including socio-demographic, Fisher's Body Image, and female sexual function index (FSFI). Data were analyzed using SPSS 24 and multiple regression, Mann-Whitey, Pearson, and Spearman correlation tests.

Results: Two hundred thirty-one postmenopausal women aged $52.53 \pm 5.32$ (mean \pm SD) years old participated in the study. The mean and standard deviation of FSFI and BI of the women were respectively $19.59 \pm 11.11$ (ranges $1.2-36$ ) and $155.43 \pm 37.09$ (ranges from 46 to 230). According to FSFI, $62.8 \%$ of female sexual dysfunction (FSD) was reported. There were significant correlations between scores of total and all domains of FSFI with scores of total and all dimensions of BI. There was also a positive correlation between education and family income of the women and a negative correlation between age of husband and duration of menopause with their sexual function. Significant relationships were also shown between the women's and the husbands'jobs with the total score of women's sexual function. According to the multiple linear regression model, BI was a significant predictor of sexual function in postmenopausal women.
\end{abstract}

Conclusion: Body image is effective on the sexual function of postmenopausal women. Therefore, body image is necessary to be considered in future postmenopausal health promotion programs.

Keywords: Menopause, Sexual function body image

*Correspondence: msimbar@gmail.com

${ }^{2}$ Midwifery and Reproductive Health Research Center, Department of Midwifery and Reproductive Health, School of Nursing and Midwifery, Shahid Beheshti University of Medical Sciences, Vali-Asr Avenue, Cross of Vali-Asr and H Highway, Opposite to Rajaee Heart Hospital, 1996835119 Tehran, Iran

Full list of author information is available at the end of the article

\section{Background}

Menopause is defined as the permanent cessation of menstruation that results from the loss of ovarian function and therefore represents the end of a woman's reproductive life [1]. Along with the gradual decrease in estrogen and progesterone, which leads to complete ovarian failure and menopause, women experience physical, psychosocial, or sexual changes [2]. Perimenopausal 
hormonal fluctuations cause women to be exposed to various physical and mental disorders [3]. By the year 2030 , there will be 1.2 billion menopausal and postmenopausal women in the world [4].

Menopause is one of the factors affecting sexual function in women [5]. Most middle-aged women (approximate age 40-60) are sexually active and sex is important to them [6], however, several studies showed negative changes in female sexual function in middle age $[7,8]$.

Sexual function is the result of an interaction between vascular, neurological, and hormonal factors and also is influenced by personal and interpersonal factors, social norms as well as cultural and religious values [9]. Sexual dysfunction is defined as a clinically significant disorder in a person's ability to respond sexually or experience sexual pleasure [10]. Many women experience sexual dysfunction during menopause and the prevalence of female sexual dysfunction (FSD) among postmenopausal women is reported between 25 and $85.2 \%$ [11, 12]. A study demonstrated the prevalence of $61 \%$ FSD among postmenopausal women in Iran [13].

Postmenopausal female sexual dysfunction is a complex disorder that has many causes [1]. Reasons for these negative changes in sexual function may include biological (e.g., decreased sex hormones), psychological (e.g., the development of mood symptoms), interpersonal (e.g., sexual dysfunction in the sexual partner), and socio-cultural (e.g., negative gender stigma in older women) factors $[1,8,14]$.

Menopause is a transitory biological phenomenon, but it also marks a social passage, the significance of which varies in different cultures. It has often been regarded as a negative reinforcement of the aging process and loss of sexual attractiveness [15]. Therefore, Cultural and social context may influence how women perceive and experience sexual function during menopause [16]. A qualitative study in Iran demonstrates many Iranian women perceived menopause as the end of their sexual life [17]. A study also found that the majority of postmenopausal women pay less attention to their sexual wellbeing and consider limitations for their sexual activities [18]. Another study also showed a relationship between sociodemographic characteristics such as ethnicity and body mass index with sexual function among middle-aged Iranian women [19].

During the postmenopausal period, many women experience changes in their body, including increasing body mass index, changes in sexual organs such as sagging breasts, vaginal dryness and atrophy, and appearance of facial wrinkles or excess hair $[8,20]$ that may lead to body image dissatisfaction and mental problems [21]. Body image is a multidimensional, subjective and dynamic concept that encompasses a person's perceptions, thoughts, and feelings about their own body. It is one of the main elements of an individuals' personality [22]. These aging-associated physiological changes make the female body away from the thin-young-ideal social norm for beauty. In addition, aging modifies the life priorities and psychological status of postmenopausal women that may affect their body image throughout their lives [23]. These potentially effective factors on women's body image can in turn affect their sexual satisfaction and function [8]. There are a few studies about the body image of middle-aged women. It seems to make positive body image may improve sexual satisfaction and selfconfidence of middle-aged women $[8,24]$.

In Iran, there are over 8.5 million middle-aged women (aged 40-65 years) and more than $14.5 \%$ of the total population are women over 40 years [25]. It is estimated that by 2022 , about 5 million women will live in menopause in Iran [26]. Respecting the developing population of menopausal women and so essentiality for planning menopausal health program as well as high prevalence of sexual dysfunction and limited studies about the possible association of body image with sexual function among postmenopausal women, this study aimed to determine the correlation between body image and sexual function in postmenopausal women.

\section{Methods \\ Study design}

This study was a descriptive cross-sectional correlation study on 231 eligible postmenopausal women who were recruited from attendees to the health centers affiliated with Shahid Beheshti University of Medical Sciences in Tehran, Iran.

The inclusion criteria were: natural menopause in the recent 5 years, age $>40$, married and sexually active. The exclusion criteria were: history of medical physical and psychological diseases, occurrence of severe stress such as an accident or losing family members during the last 3 months, taking medicines containing phytoestrogens or estrogen and progesterone, and impotence husband.

\section{Sample size}

The minimum sample size was calculated to be 194, using the following formula for calculating correlation studies as below:

- The standard normal deviate for $\alpha=Z \alpha=1.96$

- The standard normal deviate for $\beta=Z \beta=0.84$

- $\mathrm{C}=0.5^{*} \ln [(1+\mathrm{r}) /(1-\mathrm{r})]=0.2027$

- Total sample size $=N=[(Z \alpha+Z \beta) / C] 2+3=194$

Considering 20\% probability of loss 231 samples were recruited. 


\section{Sampling}

A multi-stage sampling method was performed for the recruitment of the subjects of the study. In the first stage, eight health centers were randomly selected by the randomization option of Excel from four geographic districts of Tehran. Then quota sampling was performed to recruit menopausal women with inclusion criteria in the selected centers $(28$ samples from each selected 6 centers in north, east and west districts; and 63 samples from the two centers in south district). The eligible participants complete the written consent and then the questionnaires were filled up by an interview.

\section{Measures}

Three questionnaires were used for data collection including a researcher-made Socio-demographics questionnaire, the Fisher body image questionnaire [27], and the Rosen et al. Female Sexual Function Index (FSFI) questionnaire [28].

The socio-demographics questionnaire The questionnaire contains 22 questions including demographic, socio-economic, and fertility history questions.

Female sexual function index (FSFI) The questionnaire consists of 19 questions and measures women's sexual function in six domains including (desire, arousal, lubrication, orgasm, satisfaction, and pain). The minimum and maximum of all domains except desire are zero to 6.0 and for desire 1.2-6.0. The total score of scale is obtained by the addition of the scores of the six domains. The total score of FSFI is between 1.2 and 36, and higher scores show better sexual function. FSFI assess the sexual function of women during the past 4 weeks. A total score equal to or less than 26.55 is considered as FSD $[28,29]$. The reliability and validity of the Persian version of the FSFI questionnaire were confirmed by Mohammadi et al. [29] and Fakhri et al. [30]. Nazarpour and colleagues also showed Cronbach's alpha 0.938 and Intra-class correlation coefficient 0.997 [31].

The fisher body image questionnaire It was developed by Fisher in 1970 and includes 46 items. The items are scored from 1 to 5 for very dissatisfied, dissatisfied, average, satisfied, and very satisfied, respectively. The total score ranges from 46 to 230 and high scores show positive body image. The dimensions include: head and face (12 items), upper limbs (10 items), lower limbs (6 items) and the other 18 items measure the subject's attitudes toward general body characteristics [32]. The validity of the test was assessed in Iran $[32,33]$. In a study by Nazarpour and Khazai [34], the reliability of the Fisher body Image questionnaire was shown by $\alpha$-Cronbach, Spearman, Guttman Split-half coefficient of 0.918, 0.861, and 0.861, respectively. Test-retest Pearson correlation coefficient 0.84 was also calculated in the previous studies $[32,33]$.

\section{The procedure of the study}

After assessment of the inclusion criteria of the women, a written consent form was obtained and then the questionnaires were completed using face-to-face interviews with the eligible participants by the interviewers who were trained by the researchers. Face-to-face interviews were used to improve the accuracy of responses to the questions as the researchers predicted that some of the respondents would be illiterate.

\section{Statistical analysis}

The data were analyzed using the SPSS version-24 statistics software. The correlation coefficients were calculated by using the Pearson correlation test for quantitative variables with normal distribution and the Spearman correlation test for ranked and non-normal variables. Mann-Whitey test was also used to compare groups. Multiple linear regression was used to determine the predictors of sexual function.

Our assumption for the multiple linear regression model was that sexual function (FSFI) was related to body image. In multiple linear regression, the total FSFI score was considered as the dependent variable, and the total score of body image was considered as the main independent variable. Age, age of husband, duration of menopause, the job of women and her spouse, educational level of women and her spouse, the adequacy of Monthly income were considered as the potential confounding variables and so included in regression models. These variables were shown to be associated with sexual function [12].

The level of significance was set at $P$ less than 0.05 .

\section{Results}

Two hundred and thirty-one postmenopausal women with an average age of $52.53 \pm 5.23$ (Mean $\pm S D$ ) years old participated in the study. Age of menopause and duration of menopause were $50.28 \pm 4.83$ and $2.22 \pm 1.49$ years, respectively. Socio-demographic and obstetrics characteristics of women are shown in Table 1.

The mean score for FSFI was $19.59 \pm 11$ (ranges 1.2-36). FSD was observed in $62.8 \%$ of postmenopausal women. Mean scores of FSFI and its domains are presented in Table 2.

The mean score of body image was $155.43 \pm 37.09$ (ranges from 46 to 230). Mean scores of body image and its domains are presented in Table 2.

The results of the study demonstrated the positive significant correlations between total score and scores for all domains of sexual function, with the total score 
Table 1 Socio-demographic characteristics of the postmenopausal women $(n=231)$

\begin{tabular}{|c|c|}
\hline Variables & Mean $\pm \mathrm{SD} / \mathrm{n}(\%)$ \\
\hline Age (years) & $52.53 \pm 5.23$ \\
\hline Age of husband (years) & $56.96 \pm 7.82$ \\
\hline Duration of menopause (years) & $2.22 \pm 1.49$ \\
\hline Age of menopause (years) & $50.28 \pm 4.83$ \\
\hline Gravida & $3.42 \pm 1.52$ \\
\hline Parity & $2.96 \pm 1.48$ \\
\hline Live child & $2.88 \pm 1.32$ \\
\hline Still birth & $0.07 \pm 0.33$ \\
\hline \multicolumn{2}{|l|}{ Education } \\
\hline Illiterate & $10(4.3)$ \\
\hline The literacy level of reading and writing & $36(15.6)$ \\
\hline Under diploma & $48(20.8)$ \\
\hline Diploma & $80(34.6)$ \\
\hline Graduate diploma & $10(4.3)$ \\
\hline Bachelor & $33(14.3)$ \\
\hline Master of science (M.Sc.) & $10(4.3)$ \\
\hline Doctorate & $3(1.3)$ \\
\hline \multicolumn{2}{|l|}{ Education of husband } \\
\hline Illiterate & $3(1.3)$ \\
\hline Literacy level of reading and writing & $23(10.0)$ \\
\hline Under diploma & $32(13.9)$ \\
\hline Diploma & $75(32.5)$ \\
\hline Graduate diploma & $24(10.4)$ \\
\hline Bachelor & $59(25.5)$ \\
\hline Master of science (M.Sc.) & $8(3.5)$ \\
\hline Doctorate & $4(1.7)$ \\
\hline \multicolumn{2}{|l|}{ Woman's job } \\
\hline Housewife & $154(66.7)$ \\
\hline Employed & $57(24.7)$ \\
\hline Retired & $20(8.7)$ \\
\hline \multicolumn{2}{|l|}{ Husband's job } \\
\hline Employed & $147(63.6)$ \\
\hline Retired or unemployed & $83(35.8)$ \\
\hline \multicolumn{2}{|l|}{ Homeownership status } \\
\hline The owner & $149(64.5)$ \\
\hline Non-owner & $82(35.5)$ \\
\hline \multicolumn{2}{|l|}{ The adequacy of family monthly income } \\
\hline Inadequate & $94(40.7)$ \\
\hline Adequate & $137(59.3)$ \\
\hline
\end{tabular}

a Menopause is defined as the time when there are no menstrual periods for 12 consecutive months

and scores of all dimensions of body image $(P<0.001)$ (Table 3).

The results showed significant positive correlations between the total score of FSFI and the participant's level of education $(P<0.001, \mathrm{r}=0.267)$, the adequacy of their family monthly income $(P=0.021, \mathrm{r}=0.154)$. Also,
Table 2 The mean and standard deviation of postmenopausal women's scores of body image and sexual function (FSFI)

\begin{tabular}{lc}
\hline Variables & $\begin{array}{l}\text { Score } \\
\text { Mean } \pm \text { SD }\end{array}$ \\
\hline Body image & \\
Head and face & $41.11 \pm 9.87$ \\
Upper limbs & $34.31 \pm 8.40$ \\
Lower limbs & $20.01 \pm 5.59$ \\
Overall & $60.07 \pm 15.00$ \\
Total body image & $155.43 \pm 37.09$ \\
FSFI & \\
Desire & $3.24 \pm 1.45$ \\
Arousal & $3.00 \pm 2.09$ \\
Lubrication & $3.15 \pm 2.27$ \\
Orgasm & $3.45 \pm 2.15$ \\
Satisfaction & $3.79 \pm 2.05$ \\
Pain & $3.03 \pm 2.38$ \\
Total FSFI & $19.59 \pm 11.11$ \\
\hline
\end{tabular}

significant negative correlations were observed between the total score of FSFI score and the age of the spouse $(P=0.032, \mathrm{r}=-0.144)$ and the duration of menopause $(P=0.001, \mathrm{r}=-0.214)$ (Table 4).

The total score of FSFI of employed people was significantly higher than non-employed people (housewives and retirees) $(P=0.001)$. Also, the women with employed husbands had significantly higher FSFI scores $(P<0.001)$ compared to the women with retired or unemployed husbands (Table 4).

The model of multiple linear regression predicts $25 \%$ of the total score of female sexual function of postmenopausal women. The results of linear multiple regression showed that body image is a potential predictor of sexual function; So that for each unit of increase in the total score of body image, the total score of sexual function increases by 0.09 units $(P<0.001)$. Based on the model, female education $(P=0.002)$, husband's job $(P<0.001)$, were also the potential predictors of postmenopausal women's sexual function (Table 5).

\section{Discussion}

This study aimed to assess the relationship between body image and sexual function in postmenopausal women. This study showed a significant positive correlation between body image and sexual function of postmenopausal women. It also demonstrated positive significant correlations between all domains of sexual function (desire, arousal, lubrication, orgasm, satisfaction, and pain) with all dimensions of body image. The multiple linear regression model also shows for each unit of increase in the total score of body image, the total 
Table 3 Correlations between sexual function (FSFI) and the body image $(n=231)$ of postmenopausal women

\begin{tabular}{llllll}
\hline Domains & \multicolumn{2}{l}{ Body image } & & \\
\cline { 2 - 6 } & Head and face & Upper limbs & Lower limbs & Total & Total body image \\
\hline Sexual function & $\mathbf{r}$ & $\mathbf{r}$ & $\mathbf{r}$ & & $\mathbf{r}$ \\
Desire & & & & $0.323^{*}$ & $0.366^{*}$ \\
Arousal & $0.328^{*}$ & $0.392^{*}$ & $0.371^{*}$ & $0.271^{*}$ & $0.331^{*}$ \\
Lubrication & $0.318^{*}$ & $0.368^{*}$ & $0.347^{*}$ & $0.334^{*}$ & $0.392^{*}$ \\
Orgasm & $0.357^{*}$ & $0.422^{*}$ & $0.436^{*}$ & $0.301^{*}$ & $0.351^{*}$ \\
Satisfaction & $0.328^{*}$ & $0.381^{*}$ & $0.388^{*}$ & $0.261^{*}$ & $0.339^{*}$ \\
Pain & $0.338^{*}$ & $0.400^{*}$ & $0.409^{*}$ & $0.313^{*}$ & $0.370^{*}$ \\
Total score & $0.330^{*}$ & $0.387^{*}$ & $0.404^{*}$ & $0.327^{*}$ & $0.394^{*}$
\end{tabular}

${ }^{*} P<0.001$; Test: Pearson correlation coefficient

Table 4 The correlation between socio-demographic factors and sexual function of the postmenopausal women $(n=231)$

\begin{tabular}{llr}
\hline Socio-demographic factors & \multicolumn{2}{l}{$\begin{array}{l}\text { Sexual function } \\
\text { score of FSFI) }\end{array}$} \\
\cline { 2 - 3 } & \multicolumn{1}{r}{$\boldsymbol{r}^{\mathbf{a}}$} & \multicolumn{1}{c}{$\boldsymbol{P}$} \\
\hline Spearmen correlation test & & \\
Age & $r=-0.117$ & 0.081 \\
Age of husband & $r=-0.144$ & 0.032 \\
Age of menopause & $r=-0.068$ & 0.312 \\
Duration of menopause & $r=-0.214$ & 0.001 \\
Duration of marriage & $r=-0.095$ & 0.159 \\
Education & $r=0.267$ & $<0.001$ \\
Education of husband & $r=0.085$ & 0.207 \\
The adequacy of family monthly income & $r=0.154$ & 0.021 \\
Mann-Whitney test ${ }^{b}$ & & \\
Woman's Job & $z=-3.479$ & 0.001 \\
Husband's Job & $z=-5.041$ & $<0.001$ \\
Homeownership status & $z=-0.756$ & 0.449
\end{tabular}

${ }^{a} r$ : Spearmen correlation was used for data analysis since the data were numerical variables with non-normal distribution; ${ }^{b}$ Mann-Whitney Test was used for data analysis as the educational level, and the adequacy of family monthly income were ordinal variables score of sexual function increases by 0.09 units. Consistent with these results, various studies emphasize the role of body image in various aspects of sexual activity and sexual function of postmenopausal women $[8,35,36]$. In a similar cross-sectional study on middle-aged women by Afshari et al. in Iran, there were significant correlations between body image with the women's sexual function (FSFI) and all its domains. They demonstrated that women with a positive body image had a higher score of sexual function, comparing to women with a negative body image. In their analysis, the women's satisfaction with the shape of the body was a predictor of sexual function [35]. However, they used Body Shape Questionnaire (BSQ) for body image measurement. Thomas and colleagues in their qualitative study in Pennsylvania and on 45-60 years middle-aged women explored that women's body image is an important actor for their sexual satisfaction and attractiveness [8]. Although the study by Thomas et al. was not conducted on middle-aged women, and not specifically on postmenopausal women, the participants were aged in the menopausal age range. Pujols and colleagues also demonstrated a positive association

Table 5 Multiple linear regression to assess potential predictors for the menopausal women sexual function

\begin{tabular}{|c|c|c|c|c|c|c|}
\hline \multirow[t]{3}{*}{ Predictors } & \multicolumn{6}{|c|}{ Multiple linear regression } \\
\hline & \multirow[t]{2}{*}{ B } & \multirow[t]{2}{*}{ Beta } & \multirow[t]{2}{*}{$T$} & \multirow[t]{2}{*}{$P$ value } & \multicolumn{2}{|c|}{$\begin{array}{l}95 \% \text { Confidence Interval } \\
\text { for B }\end{array}$} \\
\hline & & & & & Lower & Upper \\
\hline Body Image & 0.088 & 0.289 & 4.482 & $<0.001$ & 0.049 & 0.127 \\
\hline Job of husband & 5.780 & 0.248 & 4.000 & $<0.001$ & 2.932 & 8.629 \\
\hline Education ${ }^{b}$ & 1.451 & 0.199 & 3.169 & 0.002 & 0.548 & 2.354 \\
\hline
\end{tabular}

${ }^{a}$ Classification of Job of husband:0. Retired or unemployed, 1. Employed

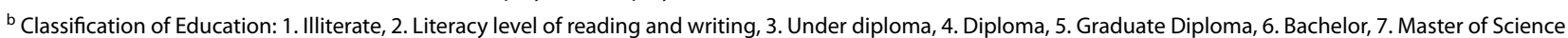
(M.Sc.), and 8. Doctorate 
between body image, sexual function, and sexual satisfaction. The study found that several aspects of body image, including weight concerns, physical condition, sexual attractiveness, and mental preoccupation with appearance during sexual activity, predict the sexual satisfaction of women [37]. Also, concentrating on decreasing menopause related physical complications, negative attitudes and feelings, concerns and psychological complications are also recommended for improving sexual function of post-menopausal women [38].

Physical changes, especially weight gain, are common in middle age [8]. Besides, the occurrence of menopause along with the physical and psychological changes may lead to negative feelings about attractiveness and body image. So, it seems menopause can hurt sexual satisfaction as one aspect of sexual function. A study in South Korea on middle age perimenopausal women also demonstrates that menopausal symptoms were significantly associated with a sexual function that may be mediated through their body image, depression, and sexual intercourse [36]. Although this study was performed on perimenopausal women, the results are consistent with our results as we considered the first 5 years of the postmenopausal period of the participants.

Studies have also shown that low body image is associated with high levels of orgasmic disorders [39] and a positive body image and high self-acceptance of one's physical appearance are associated with appropriate orgasm and sexual function [40]. This relationship between sexual function and body image can be due to women's concentration on their body that may distract their attention from positive sexual feelings and sexual signs of their partner, which in turn may lead to reduced self-efficacy and sexual pleasure. Thus, a negative body image may reduce sexual desire, intimacy with a partner, and sexual response [39].

The finding of the present study also showed a significant positive correlation between FSFI with women's education. The multiple linear regression analysis also showed education as a predictor of FSFI. This result is consistent with similar studies $[19,41-44]$ that show education as a predicting variable for psychological complications and negative menopausal feelings with the potential negative effects on women's sexual function during menopause. The high awareness that can be gained through higher education can improve women's attitudes and thoughts about gender, reduce anxiety, and help the women to cope with menopausal changes [45].

The results of the present study showed that there is a significant negative correlation between the age of the spouse and the sexual function of postmenopausal women. This result is consistent with some other studies $[12,41,43,46]$. This association may be due to hormonal changes due to aging and its consequences on sexual partner sexual function [12], which in turn may affect female sexual function. Contrary to previous studies [12, 45], there was not a significant correlation between women's menopausal age and sexual function as we recruited women who became menopause during the last 5 years, and so, the average age of the participants was 52.5 years, and this causes the range of age variable limitation for the postmenopausal period, as we wanted to be only limited to postmenopausal period.

There was a significant negative correlation between the sexual function of postmenopausal women and the duration of menopause. There are a few studies that did not confirm this result $[47,48]$, however, a study showed menopausal women experience more sexual dysfunction during the first year of menopause than second to 5 year, but after 5 years of menopause, more dysfunction is reported with increasing age. This result may be due to the menopausal symptoms caused by the sudden cessation of hormones during the first year of menopause. Menopausal women may gradually adapt to the change and enjoy their sexual life after about a year [49]. This controversy is due to considering the zero to 5 years duration of menopause in our study, so further studies with a focus on the effects of duration of menopause on female sexual function are necessary.

The results of the study indicated a significant positive correlation between the women's sexual function and their family monthly income. This result is consistent with the results of other studies [12, 42, 45, 50,51]. It seems high income is associated with high quality of life and less anxiety and depression and so leading to sexual satisfaction [31, 45, 52].

According to the results of the present study, the employment of menopausal women and their husband was associated with improved sexual function. The multiple linear regression analysis also demonstrated their husband's employment was a potential predictor of sexual function. Although some other studies confirmed that women's employment is associated with better sexual function [42, 44], a study did not confirm it [53]. There was no study on the association of employment of postmenopausal women's husbands with their sexual function, but in the study of Jafarzadeh-Esfahai and colleagues, this relationship was not significant among women of different ages [54].

Therefore, it can postulate that socio-economic factors such as education, employment, and family income are associated with a higher quality of life and body image and sexual function. These factors are also effective on individuals' and societies' perceptions of gender and sexual behaviors [45]. In this accordance, to promote sexual health among postmenopausal women 
sociodemographic socio-demographic and cultural context should be considered.

\section{Strengths and limitations}

This study was performed on women during the first 5 years of menopause as we aimed to assess the association of menopausal changes on sexual function and not the effects of aging on sexual function. In addition, the study was conducted on a population of postmenopausal women with a normal distribution that reduced participation bias.

A limitation of the present study was that it was a descriptive study and so the results can only show the association of the variables, and not cause and effect relationships. So analytical studies are necessary to show the causative effect of body image on postmenopausal women's sexual function.

The second limitation was the self-reported data gathering about body image and sexual function, and also demographics characteristics that may make selfreport bias which means the deviation between the selfreported and true values of the same measure.

Besides, sexual function is a private issue of life and FSFI could be better to be self-completed. However, it was completed by interview by the trained interviewers, because a group of the participants was illiterate or low literate (40.7\% under diploma) and besides we want to be sure that the condition for filling the questionnaire is consistent for all subjects, and also to be sure about not losing any response. It should be noted that all participants were explained about the aim of the study and gave us consent to ask the questions. Besides, FSFI is a self-report of sexual function and can be completed by interview.

Furthermore, a cause of sexual dysfunction among postmenopausal women is atrophic vaginitis. However, the aim of the present study was to assess the possible correlation of sexual function and body image. As mentioned before, vaginal atrophy is a common postmenopausal complication caused by estrogen deficiency and is known as one of several suggested causes for sexual dysfunction of postmenopausal women. However, assessment of the causes of each of the two variables (sexual function and body image) were not necessary. In this study condition for participation was their menopausal duration (up to the first 5 years) and no hormone therapy to recruit samples with similar conditions in terms of atrophic vaginitis. Anyway, atrophic vaginitis can be a main cause of sexual dysfunction among postmenopausal women, and solving this problem with systemic or local hormones or lubricants [55] can be recommended to improve the both sexual dysfunction and so body image.

\section{Conclusion}

The present study showed that postmenopausal women's body image is correlated with their sexual function. Since sexual dysfunction is very common among postmenopausal women, health care providers should be aware of the relationship between dissatisfaction with body image and sexual dysfunction, and the treatment of sexual dysfunction should include obtaining information about women's attitudes towards their body image. It seems improvement of postmenopausal women's body image promotes their sexual function and then sexual satisfaction. Regarding the significant correlation between body image and sexual function of post-menopausal women and according to the prevailing culture of the society, health policies and programs should be developed to help postmenopausal women in accepting and adapting the physical and psychological changes caused by menopause, and so that to prevent hurt to their body image. It should be also emphasized that improving in socio-economic factors such as women's education, employment and income are also associated with promoting female sexual function that should be considered by major health policymakers of the country.

\section{Abbreviations \\ BI: Body image; FSFI: Female sexual function index; FSD: Female sexual dysfunction; SD: Standard deviation; SPSS: Statistical package for the social sciences.}

\section{Acknowledgements}

Not applicable.

\section{Authors' contributions}

SN developed the project, designed the concept and study, managed the data, carried out data analysis, prepared the first and revised drafts of the manuscript, edited critically the manuscript. MS developed the project, designed the concept and study, managed the data, prepared the first and revised drafts of the manuscript, edited critically the manuscript. MK, ZJT, and RS carried out data collection. HAM contributed to the study design and managed data analysis. All authors have read and have approved the final manuscript.

\section{Funding}

Not applicable.

\section{Availability of data and materials}

The datasets used and/or analyzed during the current study are available from the corresponding author on reasonable request.

\section{Declarations}

Ethics approval and consent to participate

This study was approved by the ethics committee of the Shahid Beheshti University of Medical Sciences, with the code "IR.SBMU.PHARMACY.REC.1399.160". Written informed consent was also obtained from every participant. All the study procedures were carried out under the principles in the Declaration of Helsinki 1964 and its amendments later on.

\section{Consent for publication}

This article does not disclose any personally identifiable data in any form and the privacy rights of the participants were observed. Therefore, consent to publication is not applicable here. 


\section{Competing interests}

The authors declare that they have no competing interests.

\section{Author details}

${ }^{1}$ Department of Midwifery, Chalous Branch, Islamic Azad University, Chalous, Iran. ${ }^{2}$ Midwifery and Reproductive Health Research Center, Department of Midwifery and Reproductive Health, School of Nursing and Midwifery, Shahid Beheshti University of Medical Sciences, Vali-Asr Avenue, Cross of Vali-Asr and H Highway, Opposite to Rajaee Heart Hospital, 1996835119 Tehran, Iran. ${ }^{3}$ Department of Midwifery and Reproductive Health, School of Nursing and Midwifery, Shahid Beheshti University of Medical Sciences, Tehran, Iran. ${ }^{4}$ Department of Biostatistics, School of Paramedicine, Shahid Beheshti University of Medical Sciences, Tehran, Iran.

\section{Received: 28 August 2021 Accepted: 17 November 2021} Published online: 07 December 2021

\section{References}

1. Berek JS. Berek and Novak's gynocology. 16th ed. Philadelphia: Lippincott Williams \& Wilkins (LWW); 2019.

2. El Hajj A, Wardy N, Haidar S, Bourgi D, Haddad ME, Chammas DE, et al. Menopausal symptoms, physical activity level and quality of life of women living in the Mediterranean region. PLoS ONE. 2020;15(3):e0230515.

3. Karmakar N, Majumdar S, Dasgupta A, Das S. Quality of life among menopausal women: a community-based study in a rural area of West Bengal. J Midlife Health. 2017;8(1):21-7.

4. Monteleone P, Mascagni G, Giannini A, Genazzani AR, Simoncini T. Symptoms of menopause - global prevalence, physiology and implications. Nat Rev Endocrinol. 2018;14(4):199-215.

5. Nazarpour S, Simbar M, Tehrani FR, Majd HA. The relationship between menopausal symptoms and sexual function. Women Health. 2018:58(10):1112-23.

6. Moghasemi S, Ozgoli G, Simbar M, Nasiri M. Middle-aged Iranian women's accounts of their sexual health care practices: a conventional content analysis. Int Perspect Sex Reprod Health. 2018;44(3):91-9.

7. Avis NE, Colvin A, Karlamangla AS, Crawford S, Hess R, Waetjen LE, et al. Change in sexual functioning over the menopausal transition: results from the study of women's health across the nation. Menopause. 2017:24(4):379-90.

8. Thomas HN, Hamm M, Borrero S, Hess R, Thurston RC. Body image, attractiveness, and sexual satisfaction among midlife women: a qualitative study. J Womens Health (Larchmt). 2019;28(1):100-6.

9. Ramezani Tehrani F, Farahmand M, Simbar M, Malek AH. Factors associated with sexual dysfunction; a population based study in Iranian reproductive age women. Arch Iran Med. 2014;17(10):679-84.

10. American Psychiatric Association. Diagnostic and statistical manual of mental disorders (DSM-5 ${ }^{\circledR}$ ). American Psychiatric Pub; 2013.

11. Masliza W, Daud W, Yazid MB, Shuhaila A, Hatta S, Rohaizat MH, et al. Sexual dysfunction among postmenopausal women. Clin Ter. 2014;165(2):83-9.

12. Nazarpour $S$, Simbar M, Tehrani FR. Factors affecting sexual function in menopause: a review article. Taiwan J Obstet Gynecol. 2016:55(4):480-7.

13. Nazarpour S, Simbar M, Ramezani Tehrani F, Alavi Hajdi H. Medical conditions and sexual dysfunction in post-menopausal women. Sex Relation Ther. 2019. https://doi.org/10.1080/14681994.2019.1672866.

14. Marván ML, Espinosa-Hernández G, Martínez-Garduño MD, Jasso K. Attitudes toward menopause, sexual function and depressive symptoms in Mexican women. J Psychosom Obstet Gynaecol. 2018;39(2):121-7.

15. Gosden RG. Menopause. In: Birren JE, editor. Encyclopedia of gerontology. 2nd ed. New York: Elsevier; 2007. p. 151-9.

16. Hakimi S, Simbar M, Ramezani Tehrani F, Zaiery F, Khatami S. Women's perspectives toward menopause: a phenomenological study in Iran. J Women Aging. 2016;28(1):80-9.

17. Rimaz S, Zareie F, Shamsalizadeh N. Iranian women's understandings of menopause and cultural scenarios. J Sch Public Health Inst Public Health Res. 2013;11(1):1-16.

18. Javadivala Z, Merghati-Khoei E, Underwood C, Mirghafourvand M, Allahverdipour $\mathrm{H}$. Sexual motivations during the menopausal transition among Iranian women: a qualitative inquiry. BMC Womens Health. 2018;18(1):1-10.

19. Merghati-Khoei E, Sheikhan F, Shamsalizadeh N, Haghani H, Yousofnia Pasha YR, Killeen T. Menopause negatively impacts sexual lives of middle-aged Iranian women: a cross-sectional study. J Sex Marital Ther 2014;40(6):552-60.

20. Montemurro B, Gillen MM. Wrinkles and sagging flesh: exploring transformations in women's sexual body image. J Women Aging. 2013;25(1):3-23.

21. Dehghani M, Chehrzad M, Jafari Asl M, Soleimani R. Evaluate the relationship between body image satisfaction with the socio-cultural patterns Teenage girls in Rasht. J Hamadan Nurs Midwifery. 2013;20(3):26-34.

22. Moradhaseli M, Manteghi M. Identification process related to development of body image in female adolescents' users of cyberspace in Iran: a qualitative study. J Res Psychol Health. 2017;11(3):62-83.

23. Kilpela LS, Becker CB, Wesley N, Stewart T. Body image in adult women: moving beyond the younger years. Adv Eat Disord. 2015:3(2):144-64.

24. Woertman L, Van den Brink F. Body image and female sexual functioning and behavior: a review. J Sex Res. 2012;49(2-3):184-211.

25. Statistics Center of Iran. Results of population and housing census 2011. Tehran: Statistics Center of Iran; 2012.

26. Namazi M, Sadeghi R, Moghadam ZB. Social determinants of health in menopause: an integrative review. Int J Womens Health. 2019;11:637-47.

27. Fisher S. Body Experience in fantasy and behavior. New York: Appleton Century Croftsm, Meredith Corporation; 1970.

28. Rosen C, Brown J, Heiman S, Leiblum C, Meston R, Shabsigh D, Ferguson $\mathrm{R}$, D'Agostino R. The female sexual function index (FSFI): a multidimensional self-report instrument for the assessment of female sexual function. J Sex Marital Ther. 2000;26(2):191-208.

29. Mohammadi K, Heidari M, Faghih Zadeh S. Validity of the Persian version of female sexual function index-FSFI scale as the female sexual function index. J Payesh. 2008:7(2):269-78.

30. Fakhri A, Pakpour AH, Burri A, Morshedi H, Zeidi IM. The female sexual function index: translation and validation of an Iranian version. J Sex Med. 2012;9(2):514-23.

31. Nazarpour S, Simbar M, Ramezani Tehrani F, Alavi Majd H. Quality of life and sexual function in postmenopausal women. J Women Aging. 2018;30(4):299-309.

32. Fisher body image test, 1 st edn. Tehran: Testing company of Yar Puya; 2010

33. Asgari P, Pasha GR, Aminiyan M. Relationship between emotion regulation, mental stresses and body image with eating disorders of women. Andisheh Va Raftar (Appl Psychol). 2009:4(13):65-78.

34. Nazarpour S, Khazai K. Correlation between body image and coping styles with severity of primary dysmenorrhea. J Fundam Ment Health. 2012;14(56):344-55

35. Afshari $P$, Houshyar Z, Javadifar N, Pourmotahari F, Jorfi M. The relationship between body image and sexual function in middle-aged women. Electron Physician. 2016;8(11):3302-8.

36. Hong JH, Kim HY, Kim JY, Kim HK. Do psychosocial variables mediate the relationship between menopause symptoms and sexual function in middle-aged perimenopausal women? J Obstet Gynaecol Res. 2019;45(5):1058-65

37. Pujols Y, Seal BN, Meston CM. The association between sexual satisfaction and body image in women. J Sex Med. 2010;7(2 Pt 2):905-16.

38. Hakimi S, Simbar M, Tehrani FR. Perceived concerns of Azeri menopausal women in Iran. Iran Red Crescent Med J. 2014;16(5):e11771.

39. Horvath $Z$, Smith $B H$, Sal D, Hevesi K, Rowland DL. body image, orgasmic response, and sexual relationship satisfaction: understanding relationships and establishing typologies based on body image satisfaction. Sex Med. 2020:8(4):740-51.

40. Hevesi K, Gergely Hevesi B, Kolba TN, Rowland DL. Self-reported reasons for having difficulty reaching orgasm during partnered sex: relation to orgasmic pleasure. J Psychosom Obstet Gynaecol. 2020;41(2):106-15.

41. Chedraui P, Pérez-López FR, Sánchez H, Aguirre W, Martínez N, Miranda O, Plaza MS, Schwager G, Narváez J, Quintero JC. Assessment of sexual function of mid-aged Ecuadorian women with the 6-item female sexual function index. Maturitas. 2012;71(4):407-12.

42. Gumussoy S, Kavlak O, Donmez S. Sexual function and Dyadic adjustment in women with urinary incontinence. Pak J Med Sci. 2019;35(2):437-42. 
43. Pérez-Herrezuelo I, Aibar-Almazán A, Martínez-Amat A, Fábrega-Cuadros R, Díaz-Mohedo E, Wangensteen R, et al. Female sexual function and its association with the severity of menopause-related symptoms. Int J Environ Res Public Health. 2020;17(19):7235.

44. Zhou Y, Li C, Jin F, Shao H, Teng Y, Tao M. Prevalence and predictors of sexual function in midlife partnered Chinese women assessed by two simple indicators: sexual frequency and sexual desire. J Obstet Gynaeco Res. 2019;45(1):210-6.

45. Heidari M, Ghodusi M, Rezaei P, Abyaneh SK, Sureshjani EH, Sheikhi RA Sexual function and factors affecting menopause: a systematic review. J Menopausal Med. 2019;25(1):15-27

46. Ishak IH, Low W-Y, Othman S. Prevalence, risk factors, and predictors of female sexual dysfunction in a primary care setting: a survey finding. J Sex Med. 2010;7(9):3080-7.

47. Charandaby SM, Rezai N, Hakimi S, Montazeri A, Khatami SPK. Sexual function in postmenopausal women and its predictive factors: a community based study in Ilam 2011. Iran J Obstet Gynecol Infertil. 2012;15(23):1-9.

48. Hashemi S, Tehrani FR, Simbar M, Abedini M, Bahreinian H, Gholami R. Evaluation of sexual attitude and sexual function in menopausal age; a population based cross-sectional study. Iran J Reprod Med. 2013;11(8):631-6.

49. Jain N, Mehra R, Goel P, Chavan BS. Sexual health of postmenopausal women in North India. J Midlife Health. 2019;10(2):70-4.

50. Smith RL, Gallicchio L, Flaws JA. Factors affecting sexual function in midlife women: results from the midlife women's health study. J Womens Health. 2017;26(9):923-32.

51. Yanikkerem E, Goker A, Cakir O, Esmeray N. Effects of physical and depressive symptoms on the sexual life of Turkish women in the climacteric period. Climacteric. 2018;21(2):160-6.

52. Nazarpour S, Simbar M, Ramezani Tehrani F, Alavi Majd H. Factors associated with quality of life of postmenopausal women living in Iran. BMC Womens Health. 2020;20(1):1-9.

53. Yazdanpanahi Z, Nikkholgh M, Akbarzadeh M, Pourahmad S. Stress, anxiety, depression, and sexual dysfunction among postmenopausal women in Shiraz, Iran, 2015. J Family Community Med. 2018;25(2):82-7.

54. Jafarzadeh Esfehani R, Fazel N, Dashti S, Moshkani S, Haghighi Hasanabad F, Foji S, Kamalimanesh B. Female sexual dysfunction and its associated risk factors: an epidemiological study in the North-East of Iran. J Midwifery Reprod Health. 2016;4(1):498-505.

55. Nazarpour S, Simbar M, Ramezani Tehrani F, Alavi Majd H. The impact of a sexual enhancement program on the sexual function of postmenopausal women. Climacteric. 2016;19(5):506-11.

\section{Publisher's Note}

Springer Nature remains neutral with regard to jurisdictional claims in published maps and institutional affiliations.

Ready to submit your research? Choose BMC and benefit from:

- fast, convenient online submission

- thorough peer review by experienced researchers in your field

- rapid publication on acceptance

- support for research data, including large and complex data types

- gold Open Access which fosters wider collaboration and increased citations

- maximum visibility for your research: over $100 \mathrm{M}$ website views per year

At BMC, research is always in progress.

Learn more biomedcentral.com/submissions 